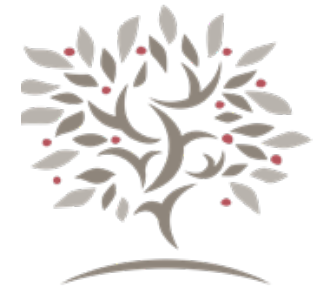

SPECIAL TOPIC

\title{
Teaching "Greek for Ministry" in a Multicultural Classroom
}

\author{
Eunyung Lim \\ Lutheran School of Theology at Chicago
}

\begin{abstract}
Teaching and learning a biblical language such as Greek can pose a set of pedagogical challenges in a multicultural classroom where the instructor and students have different cultural assumptions about language learning. Reflecting on her encounter with a student's question regarding why ancient Greek grammar operates the way it does, the author explores how this critical incident helped her recognize the cultural diversity in the classroom and develop a new pedagogical toolkit. In particular, the author employed multisensory activities using music and visuals to foster the students' motivation and bridge the gaps between different cultural assumptions. This experience eventually led the author to another pedagogical insight: Teaching and learning Greek at a seminary are critical to building much-needed intercultural competency for informed ministry in the twenty-first century. This is one of three essays published together in a special topic section of this journal on critical incidents in the classroom.
\end{abstract}

\section{KEYWORDS}

Greek, biblical language, second-language learning, pedagogy, cultural diversity, activity-based learning, multisensory teaching, intercultural competency, seminary education, ministry

“Professor, I don't mean to challenge you, but could you please explain to me why the Greek personal pronouns are declined so varyingly while some of the forms sound exactly the same?"

There was almost dead silence when a student interjected this question in the middle of my lecture.

"I am not challenged, and that's a very good question, but..."

But. . what? While I was searching for words, I looked around the classroom and immediately noticed some faces tense with vexation and others full of curiosity. Inevitably, it took me some time to process the contrasting body language in order to find the right tone and length for my answer. However, I do not remember what I said to the student. My primary memory of the incident is of having no clear answer to provide at that moment.

Only three weeks into the fall semester of 2018, this "critical incident" happened in my "Greek for Ministry" class, a pathway course to biblical studies at the Lutheran School of Theology at Chicago. ${ }^{1}$ My classroom consisted of fourteen mostly first-year MDiv students in their twenties. Although the majority had no previous experience learning a biblical or ancient language, they courageously chose this course before taking other Bible classes, with much hope and excitement that they would be able to read the New Testament in Greek. However, soon after the semester began, my students' enthusiasm started to

1 For the definition of "critical incidents" in teaching, see Brookfield (1995, 114-139). 
cool. They quickly began to struggle with the horrendous number of paradigms they had to memorize before moving on to the next lesson. Certainly, I had predicted that learning this archaic language would by no means be easy for anyone. In all honesty, however, I had not taken care to dig deeply into the realm of "why?" until the student asked me the question. As a first-year faculty member, I was busy preparing to explain grammar rules and functions, assuming that students would eventually digest whatever was written in the textbook and whatever they were told to memorize. ${ }^{2}$

However, the unexpected question my student raised alerted me to a fundamental aspect of teaching: Instructors' assumptions about their classes do not necessarily match the assumptions that students bring to the classroom. Even among students, a variety of cultural and educational backgrounds have affected their expectations about the course subject-in this case, about how an ancient language works. As I reflected on this critical incident that fall, I realized how important it is to acknowledge such different assumptions, especially when teaching in a multicultural classroom. This essay is a story about how I worked with different cultural assumptions and learning styles and about the pedagogical insight I gained in this process. The critical incident led me not only to develop a set of creative teaching strategies but also to see the benefits of language learning in a twenty-first-century seminary context.

Since the tense moment I experienced in class, I have long thought about the implications of the "why" question for my teaching. In fact, for the rest of that semester, I often witnessed puzzlement, if not confusion, about why ancient Greek grammar operates the way that it does, not only from the particular student who raised the question but also from others. Yet, as I started seeing certain patterns in their struggles, the grounds for my students' uncertainty and curiosity became clear to me. Those "why" questions stemmed from their native languages-mostly English-because their mother tongues were so natural for them that they had not considered that other language systems might work differently. ${ }^{3}$ One of the reasons the varying endings of a Greek noun posed a challenge to my students is that they had never used different endings to nouns in a sentence to express a syntactical relationship. For instance, in an English sentence like "I love coffee," we know that the noun "coffee" functions as the direct object of the verb "love" because "coffee" comes right after the verb. In other words, we do not need to add a different suffix to the noun in order to establish this relationship; the word order signifies it. Most students are used to basic English rules like this example, but Greek presents many cases of complex grammar and usage that do not exist in English. For the majority of my students who grew up speaking only English, certainly the natural basis on which to understand another language is English. They tend to assume that English grammar principles, syntax, and nuances will likely apply to ancient languages as well.

In order to learn Greek as it is, then, it seemed essential for them to break this habit of English-grounded thinking. However, would emphasizing the huge linguistic difference between Greek and English be pedagogically effective? Or, would any linguistic theory or etymological study help to reorient students toward a Greek way of thinking? In a speed-learning class like mine, it was nearly impossible to dive into the deep reservoir of history and culture within which a particular language's grammatical structures and usage are firmly embedded. Thus, it would make no sense to track down all the origins of the Greek grammar and morphology over one semester. In fact, the most honest and least time-consuming approach to learning Greek would be to just accept the way things are in that language.

When my thoughts arrived at this reality, I could finally recognize another kind of difference in the classroom that was significantly affecting my teaching. Before the critical incident, I had not realized that there may be a huge gap between my students' language learning experience and mine. Although it is true that ancient Greek and my mother tongue (Korean) have no cognation with each other, I am used to working with a heavily inflected language, as Korean has a complex grammar system in which varying endings of a verb indicate tense, mood, voice, and even the degree of respect. Moreover, whether consciously or unconsciously, I am already accustomed to accepting the ways things are in several different languages, partly because of the excruciating language requirements that I had to complete during my doctoral program and because learning foreign languages (such as English and German) was an essential part of the general education curriculum while

\footnotetext{
2 In retrospect, my past self seems to have believed that there is no better pedagogy than the traditional "banking model" when it comes to language learning (cf. Freire 2005, 71-86). In this "banking model" of education, "the students are the depositories and the teacher is the depositor. Instead of communicating, the teacher issues communiqués and makes deposits which the students patiently receive, memorize, and repeat” (Freire 2005, 72).

3 According to Robert M. DeKeyser, five different variables “interact in L2 [i.e., second language] acquisition: the characteristics of the L2, the influence of the first language ( $\mathrm{L} 1$ ), the role of age, the role of individual differences in cognitive and affective 'aptitudes,' and the role of learning context, be it the native-speaking environment or the classroom" $(2005,2)$. The author notes that "[w] here the semantic system of the L1 is different from that of the L2, ... the learning problem is serious and long lasting" (5) and introduces several cases in which learners find it difficult to establish the form-meaning link in a second language due to the absence or redundant presence of certain grammatical rules they are familiar with (DeKeyser 2005, 7-11; see also 13).
} 
I was growing up in South Korea. However, my students' experiences contrasted sharply with mine when I looked into their profiles. ${ }^{4}$ I noticed that only three or four students could actually speak or read a second language; the rest of my class had yet to learn a language other than English. Thus, my experience was not something that I could generalize to my students. Rather than asking them to break their habit of thinking in English, I should have stopped taking for granted that my students would learn Greek in the same manner that I did! ${ }^{5}$

Clarifying my own and my students' different assumptions was a turning point in my class preparation. I put away my vague hope and expectation that my students would digest lessons without difficulty and began to remind myself that telling them to unconditionally accept "the way things are in Greek" is not the best way to teach this language. However, I could not water down what my students were supposed to learn. In addition, it was neither efficient nor pedagogically inspiring to ask them to rely heavily on translation software and online morphological analysis tools when they had yet to learn key Greek terms and basic grammar rules. Therefore, I instead chose to acquire a new pedagogical toolkit, embracing my students' uncertainty and curiosity while fostering their motivation. ${ }^{6}$ What kinds of learning methods, then, has my class adopted since the critical incident?

First, I learned that it is pedagogically productive to teach from commonality rather than from difference between languages. This is also a basic step in acknowledging students' background knowledge and cultural contexts. When a certain Greek rule did not make clear sense to us, we turned to examples or analogies drawn from English (or other languages that some of my students already knew). ${ }^{7}$ For instance, as a way of showing that each language has irregularities but still presents some patterns within itself, I gleaned a case from American English. Referring to "mother," "mortal," and "mob," I encouraged my class to see that the vowel "o" can be pronounced quite differently. I also noted that although we do not know why the pronunciations are different, we can find certain patterns in the differences by learning other words in which similar consonants are placed after the "o" (e.g., "other," “orbit," and "obligation”). This comparative approach was particularly helpful when my students tried to "feel" how the Greek vowels "alpha (a), iota (I), and upsilon (U) may be short or long," depending on the word (Croy 1999, 2).

Second, we utilized a common medium of communication for all humanity: music. When the critical incident happened, my students were already overwhelmed by the different endings of the first and second declension nouns, yet they were about to learn another set of paradigms: Greek personal pronouns. If there is no other way to master them except memorization, what would help us remember them more painlessly? Having asked myself this question over and over, I finally came up with music. In the week following the critical incident, I played a YouTube recording of a funky drum loop with strong beats

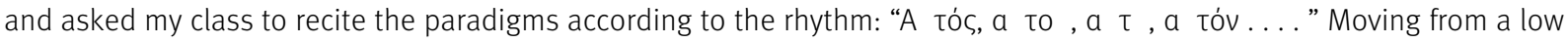
100 BPM rhythm to a faster one at 120 BPM, everyone read the Greek forms out loud, over and over again. To our pleasant surprise, the Greek paradigms turned into a rap as we tapped them out and even danced to them. Everyone left class laughing, with a clearer sense of how the Greek pronouns are declined.

Third, combining the first and the second approaches above, I often prepared multi-sensory activities that include voice, text, and visuals. ${ }^{8}$ This method particularly helped accommodate my students' different learning styles. For example, I put some famous modern songs into ancient Greek and offered a sing-along time in class. When it was time to learn the Greek imperative and $-\mu$ verbs, I did not go directly into the details of those forms and conjugations. Instead, I distributed partially translated lyrics of "Let It Go" from the Disney animation Frozen, turned on the A/V projector,

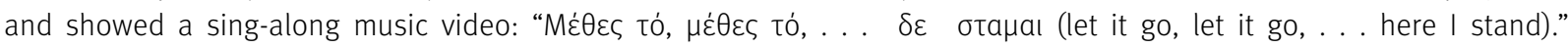
My class was singing this familiar refrain in Greek while watching Elsa's feisty acting on the screen. A possibly demanding

4 Prior to the first class meeting, I asked each student to fill out a student information sheet in order to survey my students' educational backgrounds and learning styles.

5 As Steven G. McCafferty and others point out, the focus of language teaching is on learners, not on teachers; this learner-centered approach leads to the acknowledgement that students "have a variety of second language styles," which also necessitates "the utilization of multiple strategies" to teach second languages effectively (McCafferty, Jacobs, and Iddings 2006, 24-26).

6 Fostering students' motivation is identified as a benefit of using activity-based learning in the classroom, the pedagogical principle undergirding my teaching methods. For more details, see Galindo (2020).

7 For example, when I explained that the plural form $\square \delta \varepsilon \lambda \varphi o$ in Greek could be translated as "brothers and sisters" despite its male gender, I took an example from French: the masculine plural form, "étudiants," literally means male students but it can also be used when referring to male and female students together.

8 As Linda B. Nilson shows, “all students learn more and better from multiple-sense and multi-method instruction” (2010, 237). 
Greek class turned into a karaoke, and this interactive activity helped to ease the difficulty my students would have likely felt in memorizing the conjugations.

While these teaching tools did not necessarily answer "why" questions about Greek, they at least helped keep us from getting stuck in "why's" unfathomable realm. Many of us instead found this variety of pedagogical methods engaging, effective, and even meaningful for our ongoing learning. ${ }^{9}$ The course evaluations I received from my students at the end of that semester reflect such learning experience. To quote some of them: "[Dr. Lim's class] was challenging, but she made it engaging and I enjoyed the interactive nature of it. It felt more accessible than I was expecting it to be"; "I loved that she spent time putting modern songs into Greek, her use of memes, and other pop culture references throughout to engage us and make the class fun"; "[This course] gave me new insight into how learning Greek would continue to benefit my ministry." The fun multi-sensory activities helped us open our minds to this ancient language, observe its patterns, and feel the cultural ethos that was once inscrutable and so unfamiliar to us. By using interactive learning methods, both the instructor and students participated in a collective effort in which all strived to bridge the gap between different assumptions and find the commonality that exists beyond diverse cultural and educational backgrounds. ${ }^{10}$

This collective experience is precisely the reason that I believe the critical incident also led me to see the benefits of teaching and learning Greek in a multicultural seminary context. For many of my students, my class was their first time taking a course with an Asian female professor in order to learn a language that Western academia has long claimed to own. Englishspeaking students were learning ancient Greek from a Korean instructor. Apart from the complexity of the Greek language, our class already presented a lot of unpredictability and learning dynamics stemming from the demographic differences and cultural diversity. As three or even more different cultures converged in the classroom, sometimes they collided, and other times they waited to be heard and accepted. ${ }^{11}$ After all, our journey to understand Greek from diverse backgrounds encouraged us to practice patience, improve our sensitivities to linguistic and cultural differences, and revisit our own assumptions about the lives of others. Teaching and learning Greek became an important avenue along which we paused for new voices, ventured the unpredictable, and struggled to figure out other people's ways of life in a different place at a different time. As a seminary professor, I see that these attributes are much-needed for informed ministry in twenty-firstcentury America, where many different voices co-exist, but some are left unheard or even unwelcomed. In order to help seminarians build intercultural competency, we might need to teach them to learn a biblical language, preparing them to work with many "why" questions ahead.

All of a sudden, my course title made true sense to me: Greek for Ministry.

\section{BIBLIOGRAPHY}

Brookfield, Stephen. 1995. “Understanding Classroom Dynamics: The Critical Incident Questionnaire.” Becoming a Critically Reflective Teacher, 114-139. San Francisco, CA: Jossey-Bass.

Croy, N. Clayton. 1999. A Primer of Biblical Greek. Grand Rapids, MI: Eerdmans.

DeKeyser, Robert M. 2005. "What Makes Learning Second-Language Grammar Difficult? A Review of Issues." Language Learning 55, Suppl. 1: 1-25. https://doi.org/10.1111/j.0023-8333.2005.00294.X.

Freire, Paulo. 2005. Pedagogy of the Oppressed. Translated by Myra Bergman Ramos. New York, NY: Continuum.

9 This experience resonates with Brookfield's point: "The ways that culture, history, and personality determine how events are experienced ... [gave me] the idea that different people learn differently.... when [students] hear, week after week, how people sitting next to them have a completely different reaction to what goes on in class, the reason why I use a variety of approaches starts to make sense" $(1995,121)$

10 Concerning the importance of interpersonal intelligence in language-learning classrooms that "involves showing respect to others and knowing how to understand and interact successfully with peers," see McCafferty, Jacobs, and Iddings (2006, 25).

11 What we witnessed corresponds with Trinh T. Minh-ha's observation: "The understanding of difference is a shared responsibility, which requires a minimum of willingness to reach out to the unknown" $(1989,85)$. 
Galindo, Julia Hayden. 2020. "Fostering Motivation." ABLConnect: Derek Bok Center for Teaching and Learning at Harvard University. https://ablconnect.harvard.edu/fostering-motivation.

McCafferty, Steven G., George M. Jacobs, and Ana Christina DaSilva Iddings, eds. 2006. Cooperative Learning and Second Language Teaching. New York, NY: Cambridge University Press.

Nilson, Linda B. 2010. Teaching at its Best: A Research-based Resource for College Instructors. San Francisco, CA: Jossey-Bass.

Trinh, T. Minh-Ha. 1989. Woman, Native, Other: Writing Postcoloniality and Feminism. Washington, D.C.: Georgetown University Press.

\section{ADDITIONAL CONTRIBUTIONS TO THIS SPECIAL TOPIC SECTION ON CRITICAL INCIDENTS IN THE CLASSROOM}

Pearson, Thomas. 2020. "Introduction to the Special Section on Critical Incidents in Teaching." The Wabash Center Journal on Teaching 1(2): 39-40. https://doi.org/10.31046/wabashcenter.v1i2.1500.

\section{ABOUT THE AUTHOR}

Dr. Eunyung Lim is Assistant Professor of New Testament at the Lutheran School of Theology at Chicago. Her research focuses on how images of children, women, and other minorities function in early Christian discourse, with special emphasis on their sociocultural implications for both the ancient and the modern world. She received the Derek Bok Teaching Certificate from Harvard University, specializing in intercultural competency and multimodal communication. 
